\title{
Violencia simbólica y significación de los cuerpos: Tatuajes en jóvenes
}

\author{
Alfredo Nateras Domínguez
}

\begin{abstract}
Resumen
La intención de este texto es discutir el concepto de violencia en tanto problemática compleja que se expresa a través de distintos rostros. La violencia simbólica ejercida es muy visible en contra de ciertas acciones sociales y manifestaciones culturales de algunos jóvenes (por ejemplo, en la significación del cuerpo). Por esto, interesa situar la práctica del tatuaje, a partir del cual se construyen procesos de identidades duras en adscripciones juveniles como la de los "Cholos"1 y "la Mara Salvatrucha MS13"2.
\end{abstract}

Palabras clave: violencias, jóvenes, tatuajes, cuerpo, identidades.

\begin{abstract}
The intention of this text is to discuss the concept of violence as a complex problematic that is expressed through different faces. The symbolic violence executed is very visible against certain social actions and cultural manifestations of some youngs (for example, in the significance of the body. For this, the main interest the practice of tattoo, from which processes of hard identities are constructed in youth adscriptions as the ones of the "Cholos" and the "Mara Salvatrucha MS13".
\end{abstract}

Key words: violences, youngs, tatoos, body, identities.

* Mexicano. Doctorante en Ciencias Antropológicas. Profesor-Investigador de la Universidad Autónoma Metropolitana-Iztapalapa (UAM-I). Coordinador General del Diplomado: “Culturas Juveniles. Teoría e Investigación". E-mail: tamara2@prodigy. net.mx

1 Los "cholos", son un agrupamiento juvenil cuyos antecedentes se ubican en los procesos migratorios de los mexicanos/estadounidenses de la década de los cuarenta: los chicanos y los "pachucos tipo Zoot Suit", quienes armaron las primeras revueltas en contra de la discriminación racial de que eran objeto. De ahí que los "cholos" sean considerados como una cultura juvenil de frontera y la más longeva con la que se cuenta.

2 La Mara en El Salvador, significa grupo de amigos, por lo que hay distintos tipos de Maras: estudiantiles, deportivas, del barrio, callejeras y delincuenciales. En el caso de las Maras tipo pandillas y, dada la migración forzada de niños y jóvenes hacia los Estados Unidos por la guerra en El Salvador, "La Mara Salvatrucha" se origina en los Ángeles California por la década de los 80s, como una forma de reivindicación étnica ante la discriminación racial y para defenderse de los otros grupos y pandillas. Lo de la Mara es retomado como metáfora de las hormigas gigantes del África y Brasil conocidas como marabunta que van destruyendo todo a su paso. Salvatrucha alude a Salva de El Salvador y trucha, ponerse listo o "avispado". Se cuenta que la guerra entre "La Mara Salvatrucha 13 (MS-13)" y el "Barrio 18 (B-18 o MS-XV3), surgió por la disputa del territorio y el amor de una mujer. 


\section{Las violencias y su temporalidad}

Una de las características de las sociedades contemporáneas es lo correspondiente a las violencias que tejen las relaciones entre los sujetos, los grupos, las colectividades, las instituciones y el Estado. De ahí que las violencias sean una construcción sociocultural situada en un tiempo y en un espacio histórico definido que regula y configura los vínculos intersubjetivos de una manera asimétrica, es decir, las violencias siempre remiten a relaciones de poder. Y, para el caso que nos ocupa, las ejercidas contra los jóvenes son alarmantes $y$, a la vez, inaceptables, ya que se da una especie de anulación en la corporalidad del "otro".

Se caracteriza como actos de violencias a todas aquellas situaciones, sucesos y circunstancias en las cuales una de las partes es obligada o sometida a hacer algo en contra de su voluntad o dañada física o psicológicamente por el abuso del poder ejercido por "el otro o los otros". Ejemplo: cuando los aparatos policíacos arremeten, reprimen o "apañan" a los jóvenes por la simple estética corporal, es decir, si traen tatuajes o perforaciones.

Hablar de la violencia en singular es impreciso, ya que da la idea de que la violencia tiene una sola forma, como si fuese indivisa, homogénea y uniforme, cuando en realidad tendríamos que referirnos a ella en plural, en términos de las violencias sociales, ya que son explicables a partir de los procesos históricos diversos y culturales múltiples que las producen y reproducen; en otras palabras, todas las violencias son sociales.

Para Rossana Reguillo, las violencias son multiformes y se gestan principalmente a partir de las condiciones sociales y los contextos culturales que hay que develar y explicar: "[...] la dificultad de pensar la violencia unívocamente. Es necesario entender la configuración de campos diferenciados en los que esta se gesta" (Reguillo, 1999:13). De igual manera, Adriana Soto plantea la necesidad de cuestionar la violencia como unicidad y sugiere pensar las formas de violencia como objeto de estudio en tanto 
que: "[...] no todas las violencias son las mismas y [...] éstas no siempre pueden ser comparables. [...] la complejidad y opacidad del fenómeno nos obliga a tratar de comprender las particularidades del mismo" (Soto, 2002:29).

Ferrándiz y Feixa (2004) señalan que la violencia se ha segmentado (adjetivado), es multifacética, no es una esencia y además tiene la cualidad de ser dinámica. Retoman, de Philippe Bourgois (2001), cuatro dimensiones, a partir de las cuales la tipifican; hablan de la violencia política (la administrada por el Estado, las instituciones y las respuestas ante ella); la estructural (por ejemplo, la pobreza); la simbólica (la discriminación) y, la cotidiana (la interpersonal). Asimismo, plantean dos posibles enfoques al estudio antropológico de las violencias; las culturas de la violencia (postura tradicional en Antropología) y el análisis de las violencias de la cultura (perspectiva micropolítica).

Las aportaciones de Charles Tilly (2003) ayudan a entender la violencia a partir de los procesos sociales, en tanto que la ubican en la acción colectiva. Trabaja tres dimensiones: las nucleadas por las ideas (normas, valores, representaciones), las centradas en las conductas (motivos, impulsos) y las que tienen que ver con las relaciones sociales (interacción). Tilly sostiene una postura interesante con respecto a la violencia: procesual, dinámica y relacional, en el entendido de que tiene que ver con las interacciones entre los individuos, los grupos o comunidades. Incluso y, desde otra mirada disciplinar, hay cierta coincidencia con la definición que da la Organización Mundial de la Salud: "uso intencional de la fuerza o el poder físico, de hecho o como una amenaza contra uno mismo, otra persona o un grupo o comunidad, que cause o tenga mucha probabilidad de causar lesiones, muerte, daños psicológicos, trastornos del desarrollo o privaciones" (OMS, 2003).

Es claro, siguiendo a Tilly y a la OMS, que las violencias tienen que ver con los particulares vínculos y relaciones que se establecen con los otros, desde una relación de poder. Es decir, son vínculos sociales asimétricos y, sin lugar a dudas, uno de los 
principales actores, sujetos y objetos de las violencias son una parte de los jóvenes, hombres como mujeres, de los principales centros urbanos de América Latina.

Las violencias son discursos de poder a través de los cuales hablan los actores, los colectivos, las ciudades y determinados grupos sociales que tienen que ver con las tensiones y el conflicto social. Asistimos a expresiones de violencia con diferentes rostros y tesituras: autoinfligida (el suicidio juvenil), interpersonal (familiar, de pareja, comunitaria) y colectiva (social, política y económica). Además, por su naturaleza, puede ser física, sexual y psíquica (o simbólica).

Lo que deseamos resaltar con respecto al ejercicio de las violencias es el asunto de lo político, es decir, en su aspecto de conflicto que se expresa en el espacio de lo público en su dimensión de la calle, el barrio y las ciudades urbanas entre los individuos o los grupos (Swartz, Turner y Tuden, 1994).

En el caso que nos interesa, remite a esta especie de guerra protagonizada por determinados agrupamientos juveniles. Ejemplo: la "MS13", como una expresión de las violencias transnacionales ${ }^{3}$ y de la disputa en la significación del cuerpo, cuyas trayectorias están marcadas por los procesos migratorios globalizados ${ }^{4}$ y forzados, en los cuales está implicada una gran cantidad de jóvenes, hombres como mujeres de América Central.

3 Lo trasnacional alude a una o más naciones (los Estados-Nación), en otras palabras, hay una referencia explícita o particular a una nación, cuyas dimensiones más importantes están ubicadas y son trazadas en el proyecto de lo cultural y lo político (Kearney, 1995).

4 La globalización tiene que ver con los procesos sociales, económicos, políticos, culturales y demográficos que se dan entre las naciones del mundo, es decir, su característica estriba en que se intensifican y profundizan los vínculos y las interdependencias, por lo que los sucesos locales son influidos por acontecimientos que se dan en otros espacios, tiempos y latitudes muy lejanas (Kearney, 1995). Para una discusión más amplia, el lector interesado puede consultar: Ulric Beck, ¿Qué es la globalización?, Barcelona España, Paidós, 1997; Zygmunt Barman, La globalización: consecuencias humanas, Buenos Aires-México, FCE, 1998; Néstor García Canclini, La globalización imaginada, México, Paidós, 1999. 
Esto remite inevitablemente a tener que adjetivar las expresiones de las violencias al usar la palabra o el concepto, a partir de los distintos rostros y tesituras en las que regularmente se nos muestra en varios ámbitos. Así, podríamos referirnos a la violencia inter/géneros, urbana, verbal, la del narcotráfico, la del crimen organizado y cualquier otra denominación que se nos ocurra. Digamos que al concepto de violencia le pasa igual que al de la identidad y al de cultura, pues, además de su adjetivación (Krotz, 1993), cada vez más se parcializa y fragmenta, haciéndola un tanto ambigua y difícil de acotar o definir.

Sin embargo, y rescatando la aplicación didáctica de la adjetivación de las violencias, nos interesa tocar la denominada "violencia urbana", en tanto dilucidar o desmantelar ciertos mecanismos simbólicos a partir de los cuales se ha armado un imaginario social, a través de su representación, edificando una opinión pública nada favorable para gran parte de los jóvenes, específicamente los adscritos a la identificación juvenil conocida como "los cholos" $y$ "las maras".

Este tipo de violencia se sitúa en los espacios urbanos de las ciudades como pueden ser las esquinas, las calles, los barrios o todos aquellos sitios en donde se activan las socialidades entre los jóvenes, teniendo como uno de los referentes centrales sus cuerpos, alterados o decorados, a través de los tatuajes.

\section{Identificaciones corporales al límite}

Una constante a lo largo de distintos momentos y épocas históricas en nuestra sociedad mexicana de la mitad del siglo XX a la fecha es la representación social que de los jóvenes se ha hecho, a través de una serie de imágenes que están edificadas con prejuicios y estigmas alimentados las más de las veces por el miedo y el

5 Con respecto a las investigaciones desde la sociología de la juventud, tenemos un libro clásico que aborda el asunto de los "cholos", Cfr. J.M. Valenzuela (1988) ¡A la brava ese! Cholos, punks, chavos banda, El Colegio de la Frontera Norte, México. 
temor de un mundo adulto que no logra entender y comprender ciertas manifestaciones sociales y culturales de sus jóvenes, especialmente en lo que atañe a las significaciones de sus cuerpos, es decir, a la alteración y decoración a través de los tatuajes.

Veamos: en la década de los cincuenta, las imágenes sociales que dominaban la representación de lo juvenil se trazaban en las iconografías del "rebelde sin causa" de la época. Para los años sesenta, la percepción de los jóvenes era: todos estudiantes y además "revoltosos". Entrados los setenta y a partir de la brutal represión del Estado mexicano, los jóvenes son colocados ante la opinión pública como guerrilleros y subversivos. En los ochenta, ante la explosión demográfica y la crisis estructural del estado benefactor, los "chavos banda" emergen con su expresión más radical y anárquica a través de la escena punk, alterando y decorando sus cuerpos con tatuajes y perforaciones, por lo que se les tacha de delincuentes y criminales. En la década de los noventa, se les representa como un problema social y violento. $Y$, para el 2000, los jóvenes son imaginados como apáticos, indiferentes, peligrosos, caóticos y destructores (Reguillo, 2000; Soto, 2002).

En este sentido, tales imaginarios y representaciones sociales se anclan a causa de confundir "delincuencia" con "violencia asociada a los jóvenes" (Ramos, Pérez, Romero, 1999). Además, su contenido parte de una postura "naturalista" o "esencialista", en donde prevalece la imagen hegemónica de que el ser joven, o pertenecer a determinada adscripción identitaria juvenil, es sinónimo de delincuente, peligroso, violento, perturbado, sospechoso (máxime si se traen tatuajes en el cuerpo), construido especialmente por los medios masivos de comunicación y las instancias socializadoras como la escuela, la familia y la religión.

Hay que decir que determinados jóvenes, como los que se agrupan en la adscripción identitaria conocida como los "cholillos" y la "mara", ciertamente están inmersos en contextos de violencia social muy fuertes e involucrados en los circuitos de prác- 
ticas ilegales. Sin embargo, esta violencia que viven y respiran en la calle y al interior de sus familias se hace visible a través de un tipo de organización denominado "la clika o la ganga", al estilo de las pandillas del Este de los Ángeles, California, y muy a la usanza de la lógica de las mafias italianas donde los ritos de iniciación y los códigos de honor son centrales.

En sí, "El cholo" se organiza en pandillas (gangas) que giran alrededor del barrio o la calle a la que se pertenece como es el caso de la Eighteen Street o de la primera que son de las pandillas con más tradición" (Ortiz, 1994-1995:10). Y, a diferencia de otras identificaciones juveniles urbanas como la de los "crew" o flotilla de graffiteros ${ }^{6}$ que no tienen una adscripción territorial fija, ya que, para ellos, la ciudad toda es su territorio; para los "cholillos", todavía la calle y el barrio otorgan el carnet de las identificaciones sociales de lugar.

Asimismo, hay toda una configuración de prácticas, acciones sociales, emblemas, accesorios culturales, estéticas y estilos con valor simbólico que facilitan ser reconocido y también ayudan a autorreconocerse como "cholillo". Por ejemplo, la forma de vestir recupera la ropa del obrero y del trabajo de servicio (la bandana o paliacate, la malla o red en la cabeza, los pantalones kakis y bombachos, etc.); el uso y el consumo de la música Soul, los ritmos latinos, las norteñas, el rap y el hip-hop; la gestualidad y las señas corporales para decir el nombre de la "ganga" (la clika); la alteración y decoración de los cuerpos vía tatuajes para la reafirmación del barrio y de las identificaciones locales y étnicas; el mural o el placazo como marca del territorio que incorpora elementos del graffiti; las ranflas o lo que se conoce como el "low riders" que es la decoración de autos antiguos y la vida loca que da cuenta, relata y narra la violencia en la calle y la vida cotidiana: "[...] la

6 Los del hip-hop y los graffiteros están fuertemente ligados, ya que probablemente es el movimiento juvenil más politizado y organizado en la demanda de los derechos universales y en la protesta contra la globalización neoliberal: los unos cantando y los otros rayando el inmobiliario urbano, respectivamente, interpelando así al poder y a la propiedad privada. 
violencia endémica y la drogadicción son un problema real del barrio que le ahorra trabajo a [...] la policía y a todos los hijos de su reputa madre que se sienten superiores por la deficiencia de melanina" (Ortiz, 94-95:14).

Actualmente y debido, entre otras consideraciones, a los procesos transculturales junto con sus flujos migratorios, nos encontramos con un desplazamiento de la identificación juvenil "chola" de frontera hacia una de las periferias de la ciudad de México más complejas y llamativas: Ciudad Netzahualcoyót, en el Estado de México.

A continuación, se describirán e interpretarán, a grandes rasgos, algunos aspectos centrales en la configuración de la identidad "cholilla" de NezaYork y la de la "Mara Salvatrucha MS13" de Centroamérica, a la luz del anclaje con el territorio o el barrio, la violencia entre clikas, el tatuaje como marca identitaria y el cuerpo en tanto territorio de la decisión de sí. Para esto, se dará voz a algunos jóvenes "cholos" entrevistados en los tianguis callejeros a través de la resignificación de varios testimonios ${ }^{7}$.

\section{Ser "cholillo" en NezaYork}

Los "cholos o cholines" de Ciudad Netzahualcoyótl son un agrupamiento o adscripción grupal juvenil definida y dura, entre otras cuestiones, por tener una adscripción territorial anclada todavía en el barrio, la calle, aunque están circunscritos a los flujos migratorios del norte del país, real como simbólicamente, de tal manera que traza sus trayectorias hacía lo que bien podríamos llamar como las "culturas de frontera o fronterizas".

Estas culturas de frontera o fronterizas alimentan a determinadas identificaciones juveniles muy visibles en centros urbanos

7 Se utilizan varios trozos de entrevistas individuales a profundidad, las cuales son parte de un programa de investigación en marcha desde el año 2000, denominado: "Estéticas corporales urbanas y escenas juveniles en México". Se tomaron aquellas donde aparecen referencias a los cholos. 
como Guadalajara, Jalisco, Monterrey, Nuevo León y el Estado de México, tan sólo por citar estos lugares. Y quizás sea en el Estado de México (Ciudad Netzahualcoyótl, La Paz, Los Reyes y Ecatepec) donde actualmente la escena sociocultural de los "cholillos" adquiere características muy particulares con respecto, por ejemplo, a la frontera norte del país como Tijuana, Baja California.

A diferencia de otro tipo de agrupamientos identitarios juveniles urbanos (piénsese en los "darketos") ${ }^{8}$, el asunto del territorio para los "cholillos" sigue siendo un aspecto de vida y muerte entre las diferentes "gangas o clikas", en tanto su defensa se lleva a cabo a balazos, parecida a la manera de actuar de las pandillas del Este de los Ángeles, California o de Chicago, Illinois en los Estados Unidos de Norteamérica. Y, al hablar de "ganga o clika", nos estamos refiriendo a un tipo y forma de agrupamiento al que se pertenece, entrelazado indisolublemente al aspecto del barrio, colonia o incluso minoría étnica, ya que delinea no sólo el tipo de agregación, sino el nombre de la banda a la que se pertenece con todo y una fuerte carga afectiva entre sus integrantes.

Este tipo de agrupamiento juvenil define sus aspectos identitarios en función, entre otros elementos, del espacio o territorio apropiado y usado: la esquina, la calle, el barrio mismo y otros lugares de encuentro o mejor dicho de reencuentro. Así, el barrio es el escenario donde transcurre en gran parte la sociabilidad de estos púberes, adolescentes y jóvenes "cholos".

La calle, entendida como el barrio, sigue siendo una especie de hogar donde se lleva a cabo la convivencia y el uso del tiempo libre o del ocio, entre todos, ellos y ellas. Y uno de los elementos en el uso y apropiación simbólica del barrio, los espacios y sus territorios, es la expresión callejera del muralismo cholo, el

8 Los jóvenes de la escena oscura (darketos, góticos, vampiros, fetichistas), tienen sus orígenes o descienden de los punks, aunque su protesta social y política es intimista, hacia adentro y refugiados en las artes (la música, la poesía, la literatura, el performance), les cuesta mucho los vínculos con las otras agrupaciones identitarias, en tanto que padecen una especie de narcisismo agrupado y de vanidad pública. 
cual resalta iconografías e imágenes mexicanistas que le dan un colorido muy especial al barrio. Este aspecto es simbólicamente tan importante en algunos jóvenes que el nombre del barrio o la placa con la que se identifican se lleva tatuada en el cuerpo, regularmente en el vientre, el pecho y la espalda, aunque raramente en el cuello que, además, es de las partes más dolorosas de tatuar por las terminales nerviosas y los torrentes sanguíneos que ahí transitan. Junto con la placa o el nombre del barrio, aparecen también tatuajes en sus corporalidades, con similares o las mismas imágenes o iconografías que aparecen en los muros y bardas de su barrio:

Te estás tatuando, si me platicas ¿Por qué decidiste tatuarte?

Por mi barrio, mi placa, todos están tatuados.

¿De qué barrio eres, de qué placa?

Los SOS, placa, pues es la misma: SOS.

Y ¿Qué significa SOS?

Mira, SOS: callejón del lado oscuro, pero esos SOS están escritas en inglés, placa que no me sé; nada más sé que significa eso.

¿Y qué significa para ti tu barrio, qué es para ti el barrio? Ora sí que mi segunda casa, todos mis compás, sí, mi casa, todos mis compás; mis carnales nada más.

Ahora ¿Cuando ves, o ustedes ven a otros chavos de otros barrios que también están tatuados, qué pasa?

Simplemente no tatuados, sino que aunque sea de otro barrio, hay que preguntarles ¿qué barrio? y ya depende de lo que contesten; si es tregua o hay tregua con ellos, pues pásenle, si no, pues ya mamaron, nada más. (Alejandro) ${ }^{9}$.

Este trozo de entrevista es muy contundente en el sentido del lugar real y simbólico que ocupa el barrio para este tipo de agre-

9 Entrevista individual realizada en el Tianguis del Parque del Pueblo, Ciudad Netzahualcoyótl, enero de 2000. 
gamiento juvenil, definido en función de la dificultad para reconocer al otro, de otro barrio diferente y, por consiguiente, de otra placa. En la medida en que se reconozca la diferencia, en este caso anclada con respecto al territorio, el otro o lo otro deviene como amenazante para mí y para mi barrio, por lo que es un contrario y enemigo real. Desde esta lógica, a los enemigos y contrarios, al no soportárseles, se les trata de eliminar físicamente (destruir la corporalidad como identidad) o, lo que es lo mismo, hay que desaparecerlos de este mundo terrenal.

Aquí nos encontramos con un tipo de violencia difícil de comprender, que se da, curiosamente, al interior de la misma adscripción grupal identitaria, en este caso, de los "cholillos" y escenificada y dramatizada en las calles y entre barrios, o en todos aquellos lugares o territorios donde se encuentran determinadas "gangas o clikas" como sucedió en un evento cultural al que asistí. Sucede que fui invitado por Pablo Hernández ("El Expodrido") ex líder de la legendaria banda llamada "los mierdas punks", a un evento músico/cultural de "cholillos", efectuado el 15 de julio de 2000, en la Alameda de Oriente, atrás del Aeropuerto Internacional de la Ciudad de México. Tal evento se denominó: "Paz en las Calles II. La Historia Continúa", cuya finalidad precisamente era contribuir a destensar el asunto de rivalidad entre los distintos barrios, "clikas y gangas", de Ciudad Netzahualcoyótl. Ese día, por la mañana, conversé por teléfono con el fotógrafo Federico Gama para ir juntos al evento. Llegamos al lugar más o menos como al mediodía y, al entrar a uno de los estacionamientos, nos sorprendió la llegada de varias patrullas de la policía judicial del Estado, así como dos ambulancias. Nos bajamos rápidamente de los autos en que viajábamos y nos percatamos de que dos bandas rivales se habían balaceado, dando por resultado un "chaval" como de doce años de edad herido de bala en la pierna derecha.

El evento finalmente se suspendió, quedando, entre los que estábamos ahí, un estado de ánimo colectivo de cierta incredulidad y hasta tristeza por lo ocurrido, ya que este tipo de violencia 
social es muy lamentable y además llamativa por su destructividad y en muchos sentidos su auto/destructividad. Paradójicamente, los enemigos más temibles de los cholos, más allá de la policía o de la situación económica precaria, al parecer, son ellos mismos.

Esta violencia define a este tipo de agrupamiento cuya filosofía se puede describir a través de la siguiente expresión o frase: "la vida loca". Es decir, de lo que se trata para una gran parte de ellos y ellas, es vivir la vida a todo lo que da, asumiendo los riesgos con respecto a las drogas, los problemas con la ley, las armas y otros asuntos casi siempre vividos en los umbrales de lo ilegal (identificaciones al límite), situación que nos lleva a pensar que el Estado y sus instituciones de seguridad podrían estar implicados y fomentando las situaciones de violencia social entre este agrupamiento juvenil como una buena estrategia de control. La forma y la manera en que se estaría fomentando dicha violencia es a través de la venta clandestina de armas y de droga a los jóvenes "cholos", a fin de que sean ellos mismos quienes se aniquilen y destruyan.

Otros elementos que definen en gran medida a esta adscripción grupal identitaria juvenil tienen que ver con la autoafirmación de lo mexicano, es decir, con las identidades duras, en contraposición, a lo "gabacho" o "gringo". Esta contraposición no está exenta de contradicciones, en tanto que -de inicio- se ubica en el terreno cultural reivindicando lo prehispánico. Sin embargo, después se diluye en lo que hace al estilo de vida o, si se desea, al ideal del mejoramiento socioeconómico, teniendo como imagen la forma de vida del norteamericano.

Con respecto a la reivindicación de lo mexicano, se desarrolla una especie de orgullo con respecto a la raza y la etnia, de tal manera que la alteración corporal a través del tatuaje cobra un lugar muy importante para dar cuenta del aspecto cultural o, mejor aún, de las raíces y orígenes de la cultura mexicana. Así que 
las imágenes e iconografías más llamativas en las corporalidades de los cholos, tanto de jóvenes hombres como de mujeres jóvenes, refieren a lo mexicano, vinculado y mezclado con lo prehispánico. De ahí que se encuentren imágenes tatuadas tales como escudos nacionales, mujeres charras (las charritas), nombres de la madre o de ellos o del barrio o la placa, regularmente en una tipografía con letra gótica, imágenes de lo mexicano: el Popocatepétl e Iztlaccihuátl, la Virgen de Guadalupe, Guerreros Aztecas y todo tipo de dibujos con respecto a los orígenes ancestrales.

Al mismo tiempo, a través de estas imágenes tatuadas en la piel, se resalta el orgullo de lo mexicano y, más que nada, de ser mexicano. Se trata de incorporar cierto estilo de vida de lo "gabacho o gringo" (the american way of life), portando ropa cara y de marca, zapatos o tenis ostentosos, procurar tener un auto e inclusive una buena casa con todos sus artefactos electrodomésticos para que la "jefa" o la madre, sea congraciada o retribuida.

El lugar de la madre para los jóvenes "cholos", hombres como mujeres, es central en la configuración de su adscripción grupal en tanto que a la madre siempre se le lleva en ausencia o presencia, también muy adentro de los afectos: en el lugar de lo sagrado. Por esto, no es fortuito que una de las grandes ofensas o agresiones que se le pueden hacer al otro, sea ofender a la madre con la clásica expresión ";Ve y chinga a tu madre!" Y, a diferencia de otro tipo de agregaciones juveniles urbanas, como la de los "skin head"10, la presencia de la mujer joven es muy visible entre los "cholillos", aunque a ciencia cierta no logré ubicar y comprender el lugar real y simbólico que ocupan en este tipo de agrupamiento urbano juvenil.

10 Los skin head adquieren dos vías; el ala neofascista y la de los rojos. Los neofascistas, por lo regular, provienen de las clase medias ilustradas y reivindican el nacionalismo mexicano mezclado con la idea de la pureza de la raza, en este caso, de la raza cósmica. Por otra parte, los denominados rojos defienden políticamente el anarquismo y el orgullo de ser obreros, socialistas y comunistas. 
El siguiente extracto de entrevista, realizada a un joven "cho$l 0$ " es muy elocuente con respecto a determinadas características socioculturales que hemos mencionado, asociadas a las violencias sociales, a la adscripción grupal definida como los "cholillos" y a la significación del cuerpo, vía tatuajes como una especie de relato o historia de vida, por lo que va a ser un poco extenso. $Y$ he de decir que fue de las entrevistas más difíciles que realicé, ya que, conforme transcurría, me di cuenta de que el contenido del relato era delicado, aunque muy interesante porque en algunos momentos el entrevistado (Mario), se irritó conmigo por el tipo de preguntas que le estaba haciendo y el curso que estaba tomando la entrevista, tanto que ciertas preguntas no las quiso contestar:

Ahora; el siguiente tatuaje, el cuarto: ¿Qué fue lo que te tatuaste? igual, así como me lo estas relatando, las motivaciones.

Un Cholo: Cuando llegué de Chicago Ilinois, ya llegué con onda chola; me hice ganga allá iy es otro pedo ese! es el mismo pedo de aquí de las bandas, en lo que ya son cholos.

Ahora, igual y si me dijeras ¿En qué año fue? ¿Cuántos años tenías cuando lo de tu cholo?

Después de los 19 años me metí a una ganga: me tatué el conejo que correspondía a la banda "Tutsy", en Chicago Ilinois ¡brother!

Ahora, esta cuestión de la imagen del cholo: ¿Qué es ser cholo?

Ser cholo es "mexican delincuencia", como por ejemplo, México, Mexicoamericano, yo soy mexicano y yo como me casé con esa chicana ya voy a ser residente, tengo que ser americano por fuerza, por ley, si quiero entrar y salir del país eso es lo que único que tengo que hacer.

Ahora ¿Qué más los caracteriza como cholos?

Porque somos aztecas, sangre azteca, somos familia mexicana y somos mexicanos; algunos ya somos residentes allá y hablamos los dos idiomas ¿por qué? porque somos latinos; los 
latinos no hay necesidad de que sean mexicanos, centroamericanos, seguimos siendo latinos; sabes ¿por qué? porque dominamos el idioma español.

Acá en Ciudad Neza, también hay una especie de cholos que le llaman los cholines, ¿no? ¿Cuál es la diferencia entre los cholos de allá, con los cholines de acá de Neza?

Te diré que también los de allá son bien manchados y los de aquí también iqué te diré! aquí también la banda está pesada: la "Ermita Zaragoza" es otro pedo; después la banda de los "Ojos Rojos"; "Los Tres de la Banda", "Superbanda de los Canes"; estoy hablando de banda pesada.

Los cholines de aquí ¿Qué características especiales tienen por estar en Neza, o estar en el barrio, a diferencia de lo que tú ves allá?

Te diré que es la onda que uno trae de allá, que uno llega más maleado y empieza a mover a la banda, empiezas a comprar juguetes: armas, dinero, empiezas a traer ora si que carros y dos tres ondas: joyas, alhajas, viejas, cuetes y su pinche madre, pues ya te imaginarás por qué es esa onda jentiendes! y pues ve, a todos les gusta el desmadre, es una de las formas de demostrar lo que eres.

Ahora, si me describieras ¿Qué imagen es la que te estás tatuando? ¿Por qué esa imagen? ¿Qué representa para ti?

El desmadre, la banda, de plomo si mueres; el que a hierro mata a hierro muere jentiendes! y este dibujo significa algo que hice allá y aquí también; tengo las matracas pero ahorita también después de esta, a ver qué pedo ¿no?

Antes de este tatuaje, ¿Qué fue lo que te habías tatuado hace tres años atrás, antes de este?

El nombre de mi mamá y el nombre de Los Ángeles [...] me lo hice por dos razones; porque radicaba en Los Ángeles California y era también de "Los Latin Kings" y mi mamá se llama María de los Ángeles y entonces me tatué la " $M$ " que significa María y México; Ángeles porque es de allá de Los Ángeles o 
sea que María de los Ángeles [...] México y Ángeles, eso es lo que significa para mí (Mario) ${ }^{11}$.

Como mencioné previamente, las iconografías e imágenes rayadas en el cuerpo tatuado tienden a la diversidad y a la variedad de lo que hemos denominado la adscripción grupal o las identificaciones grupales juveniles "cholas", cobran su propio sentido precisamente por estar ancladas a expresiones y manifestaciones socioculturales más amplias que lo que puede representar la imagen misma del tatuaje. Esto quiere decir que, atrás de algunas imágenes, subyacen las historias y vivencias de la vida cotidiana de violencia de los sujetos que las portan y que imprimieron para siempre en sus cuerpos. Estas vivencias suelen ser muy reveladoras, en cuanto son una ruta para entender los momentos y las trayectorias de vida de ciertos sujetos, las cuales dejaron una fuerte huella o marca que los llevó a plasmarlas para siempre en las pieles y las corporalidades urbanas.

Así, estas pieles y cuerpos tatuados pueden portar diversas historias de la trama de la vida social violenta y las vivencias de la ciudad en situaciones de riesgo extremo o de situaciones límite. Sin embargo, hay que manifestar que las figuras tatuadas en sí mismas no necesariamente remiten de manera directa y mecánica a la adscripción grupal que a primera vista y "mirada" uno deduzca sino que necesariamente tienen que explorarse en sus articulaciones y anclajes de significado y significación sociocultural.

El proceso de vida se construye con elementos de la cotidianidad, lo que lleva al tejido de una trama singular y privada, aunque construida social y colectivamente. Así, el proceso de vida está plagado de sucesos, vivencias y experiencias, algunas tan importantes que van marcando los derroteros en la existencia de determinados sujetos jóvenes, al grado de que se alteran

11 Entrevista individual realizada en el Tianguis de la cárcel, Ciudad Netzahualcoyótl, febrero de 2000. 
y decoran los cuerpos: se les plasma, graba y pinta, a través de tatuarse ciertas imágenes. La finalidad es que, en la corporalidad y la piel, vayan quedando las marcas de aquellos momentos probablemente de transición en la vida social de los sujetos jóvenes que los coloca ante el recuerdo de haber realizado cambios o transformaciones significativas con respecto a todas aquellas situaciones de su vida y los eventos que de una u otra manera fueron en extremo difíciles, complejos, decisivos y coyunturales.

De ahí que haya corporalidades con una gran cantidad de relatos, memoria e historias que yacen implícitas y latentes en los tatuajes que se porten y traigan. $Y$, aunque no sean tantos los tatuajes impresos en la piel, es factible ir reconstruyendo, en las corporalidades cholas, los avatares de la vida y la existencia de tales sujetos jóvenes, como si fuesen una suerte de historias de vida visuales o estudios de caso ambulantes. Esto es factible con los tatuajes ya que representan y dan cuenta de varios pasajes que llevan a situar las trayectorias de vida de estos sujetos.

Así, el tatuaje, en determinados casos, viene siendo una marca y un tipo de huella real de la vivencia social de violencia con un valor simbólico en ciertos casos muy elaborado, creativo, inusual y, además, plagado de metáforas, referencias personales, lugares habitados, presencia de los otros y otras, espacios transitados, tiempos idos, amores perdidos, temores fundados, miedos culturales, dualidades eternas y sucesos presentes, por demás bellos y emotivos. Y quizás podríamos decir que el tatuaje es una doble marca; la que hace a la iconografía seleccionada en tanto irreversible, como la que refiere al valor simbólico construido a través de su sentido o significado de igual manera irreversible. Por esto, estamos ante un acto sociocultural muy particular con cargas emotivas y afectivas; duras, fuertes y de una riqueza de contenidos y significados abiertos, plásticos y flexibles.

Digamos que las vivencias cotidianas y personales más significativas que se experimentan y van pintándose en las corpo- 
ralidades juveniles urbanas también van diciendo de la persona, es decir, el sujeto comunica y refiere algo con respecto a lo otro o los otros a través de la iconografía marcada en el cuerpo. De esta manera, a través de ello muestra también una forma de imaginarse, representarse e interpretarse a sí mismo: su circunstancia personal, su contexto cultural y el mundo social violento del cual forma parte y que, en varios aspectos, está implicado e incide en ellos.

La función simbólica de determinados tatuajes se centra, entonces, en mostrar la sensación de lo que uno cree ser, de lo que uno está comprendiendo de su propia vida, lo que le ha pasado y pasa a uno. Aquí encontramos lo que bien podríamos catalogar como la parte reflexiva y de racionalidad de los sujetos sociales, en este caso, de los jóvenes "cholos", hombres como mujeres; el explicarse e interpretarse a sí mismos y construir sus propios sentidos y significados con respecto a los avatares de su vida cotidiana.

Hay un mecanismo de interpretación del mundo en la medida de seguir experimentándose, para buscar o buscarse permanentemente con respecto a lo que uno fue o desea ser. Esa intencionalidad de manifestar y expresar visualmente lo que uno piensa o desea ser tiene su correspondencia con la imagen construida por los otros con respecto a uno: los otros también influyen en la propia descripción o explicación de lo que es uno.

Al imprimirse para toda la vida una determinada imagen que representa a su vez un suceso específico, un estado de ánimo, un acontecimiento violento, una postura o posición política o una situación coyuntural, se están incorporando y elaborando simbólicamente los componentes emotivos y afectivos de esas vivencias. Así, ese suceso vive para siempre en el cuerpo tatuado en tanto forma parte de su historia y tránsito por la vida como una especie de pintura rupestre o pergamino guardado en la galería personal interna. 
Dentro de los acontecimientos del proceso de vida más visibles en las pieles y las corporalidades juveniles urbanas que encontramos marcados y grabados o que por su fuerza simbólica llaman la atención sobre los demás, están los relacionados con aspectos existenciales vinculados con las dualidades de la vida y la muerte y los vínculos afectivos con "el otro" del tipo "carnal" o integrante de la misma "clika o ganga".

Estas vivencias cotidianas que tejen la trama subjetiva de los sujetos sociales jóvenes son un pensamiento binario que tiene que ver con los dilemas de la vida marcados en una parte significativa de las corporalidades juveniles urbanas "cholas", por lo que se le tatúa a través de determinadas imágenes en la piel. Esta situación del pensamiento binario aparece demasiado arraigada y se hace muy visible ya que tiene que ver con la contraposición o lucha permanente entre dos elementos o aspectos distintos entre sí, jugados en los avatares de la existencia humana. Importa decir que, sin uno de los elementos en pugna, no se puede explicar el otro; están íntimamente relacionados: uno está en el otro y éste en aquél. Los ejes más representativos a partir de los cuales se arma el pensamiento binario o dual son los ubicados en los siguientes pares: la vida/la muerte; el bien/el mal; la luz/la oscuridad; la felicidad/la tristeza; el placer/el displacer, y también con respecto a elementos como la luna/el sol; la tierra/el agua e izquierda/ derecha, por mencionar tan solo estos.

Todos estos pares están ligados y relacionados unos con otros y, para la representación gráfica del tatuaje -considerando estos binomios o dualidades- se recurre a una gran variedad de imágenes o grabados. Dentro de estos binomios o dualidades, el que más sobresale sobre los demás en el discurso oral de ciertos jóvenes "cholillos" es el de la vida y la muerte. Sorprende la presencia tan fuerte con respecto al asunto de la finitud de la existencia y la temporalidad del cuerpo en aquellos jóvenes donde las historias de sus vidas son también historias de muerte, vivencias que se dan en los ámbitos de la familia, la escuela o con la "ganga o clika". 
Probablemente, esto tenga que ver con la crudeza social de las experiencias o por todas aquellas circunstancias desfavorables que se tienen en el tránsito de la existencia, tanto que se termina tatuando en el cuerpo una marca relacionada con la muerte. Además, también cuenta el hecho de haber tenido alguna experiencia previa cercana a la muerte o con respecto a la actividad que se lleve a cabo, donde la muerte acecha constantemente. De esta forma, la muerte es la compañera inevitable en la trayectoria de la vida social de ciertos jóvenes "cholos".

Así, para ciertos jóvenes urbanos de adscripciones identitarias como los "cholines", la vida es para vivirse, disfrutarse, arriesgar y, como lo dicen ellos, es vivirse "la vida loca"; en la que al mismo tiempo algo puede salir mal y aparecer la muerte.

La dualidad expresada en la vida y la muerte se expande o extiende al binomio configurado por el bien y el mal que nos remite a un asunto moral. Por lo que el bien y el mal se van a entender a partir de lo legal como lo ilegal, respectivamente. Así, la actitud y el comportamiento que se tenga con respecto a lo legal y lo ilegal -entendidos estos como el acatamiento o no de determinadas reglas y normas que regulan la vida social entre los sujetos- van delineando las figuras que se vayan a imprimir en la piel. Así, lo legal e ilegal se juega principalmente en los vínculos y en las relaciones con los otros u otras; de ahí que tenga que ver con un aspecto del comportamiento de los sujetos; en este caso, de los "cholillos". Alude también a la manera en que un sujeto se "mira" con respecto a su proceder en determinadas situaciones o personas y, en tanto se logra "mirar", hay una especie de autorreflexión tan fuerte que lleva a ciertos sujetos jóvenes a marcarse esos sucesos en el cuerpo:

Esa imagen empezó por el desmadre, la banda, tú sabes, me tatué una rata con una matraca saliendo de un banco con el botín en la mano y la matraca en la mano [...] ese era un recuerdo, tenía unos dieciocho abriles, el tercero fue el correcaminos correteándolo [...] ese fue un asalto que también acá con una 
morra también traía estos tatuados y como ahora sí que el coyote corretea, o sea que el coyote es la policía y el correcaminos es la rata [...] por eso los dos traíamos eso, los dos ejecutamos eso [...] aquí mismo saliendo me agarró el coyote, se supone que el coyote es la tira, la morra también se lo tatuó, el coyote representa que está agarrando la rata jentiendes! (Mario) ${ }^{12}$.

\title{
4. Ser "marero": sujeto transnacional
}

\begin{abstract}
"La Mara Salvatrucha (MS-13)" y "La del Barrio-18 (MS-18 o MSXV3) son grupos de jóvenes, hombres como mujeres, en sus orígenes salvadoreños que incluye también a hondureños y guatemaltecos con características muy parecidas y similares a la de los cholos mexicanos. Por ejemplo, están inscritos en los procesos migratorios: "El Barrio-18" tiene sus orígenes en los Ángeles California, en la calle 18; de ahí la denominación y está conformada por mexicanos, chicanos, cholos, salvadoreños y demás centroamericanos. Así también se les encuentra en San Francisco, New York y Washington ${ }^{13}$.
\end{abstract}

Se tiene conocimiento de que las primeras "maras" se conformaron a finales de la década de los setenta y principios de los ochenta con niños y jóvenes callejeros, entre 12 y 25 años de edad, de los barrios pobres. Nacidos y crecidos en el periodo de la guerra en El Salvador. Hijos de combatientes, guerrilleros y guardias nacionales, vinculados al consumo de drogas y delitos menores

12 Entrevista citada, No. 1, nota 11

13 En este sentido y recurriendo a la hipótesis teórica de José Manuel Valenzuela, en el entendido de que "Los Cholos, le dan el rostro o configuran de sentido a la "Mara Salvatrucha", cobra relevancia deducir que "La MS" incorpora los rasgos identitarios de los "Cholos Mexicanos": la significación del cuerpo a través del tatuaje; la forma de organización tipo "clika" o "ganga"; escenificación de la batalla urbana por la disputa del territorio; ritos de iniciación; códigos y reglas de honor; reivindicación de la raza y la nacionalidad; administración del poder y del miedo, es decir, "La Mara" Salvadoreña, al llegar a los Ángeles California, se percata que la forma de sobrevivir en un país ajeno, es agruparse como lo vienen haciendo, al menos desde 1940, los jóvenes mexicanos "cholos". Cfr., Valenzuela José Manuel 2002 "De los pachuchos a los cholos. Movimientos juveniles en la frontera México-Estados Unidos", en Feixa, Molina y Alsinet (Coord.) Movimientos Juveniles en América latina. Pachucos, malandros, punketas, Ariel, España. 
como el robo, dedicados a trabajos como obreros, vendedores ambulantes, albañiles y en las maquiladoras. Muchos de ellos han pasado por las cárceles tanto de los Estados Unidos como en El Salvador. Su manera de agregamiento es a través de las clicas, por lo que tenemos distintos tipos de maras, las hay del barrio o callejeras, las estudiantiles y las delincuenciales o industriales (Cuerno, 2000).

En cuanto a sus prácticas sociales y expresiones culturales, también usan el cuerpo para comunicarse e identificarse como clica o ganga. Traen tatuajes, parecidos a "Los Cholos", escuchan música, más del tipo heavy metal, grafitean y plaquean en las paredes de las ciudades en su apropiación simbólica; construyen mecanismos de ritualización al ingresar al grupo: 13 minutos de golpes por parte de los mareros, igual que los cholos y, emplean una forma particular de hablar.

En sí, tanto el agrupamiento de "los Cholos" como el de las "Maras" son agregamientos de jóvenes urbanos importantes para la construcción identitaria juvenil con sus prácticas sociales y expresiones culturales muy definidas y visibles en el espacio urbano, en tanto que funcionan como grupos de pertenencia y referencia cohesionados y con lazos afectivos muy fuertes entre ellos y ellas, tanto que la negación del barrio, de la placa y del grupo, se considera una traición, por lo que se paga con la vida.

Ambos agrupamientos, en cierto sentido, son jóvenes organizados y constituidos como grupos de resistencia y de reivindicación cultural, racial y étnica, ante los otros distintos a ellos en su vivencia y experiencia de ser extranjeros y migrantes, regularmente indeseables en el país de llegada. Por lo que agruparse y reconocerse como jóvenes latinos, centroamericanos, mexicanos o salvadoreños, une y ayuda, máxime cuando lo que más consume espiritualmente es verse y sentirse alejado de la patria, de la tierra de origen, la familia y los amigos. Identidades juveniles urbanas de la nostalgia y la tristeza que transitan en los distintos 
espacios de las ciudades con el ansia de ser aceptados y caber en algún sitio, aunque sea simbólicamente hablando.

Consideramos importante resaltar la dimensión simbólica en la disputa del poder (lo político) y los mecanismos, los accesorios y los artefactos culturales a partir de los cuales se muestran y entran en la guerra de sentido y significación en este tipo de agrupamientos versus los "otros", vía las estéticas corporales, en este caso de la "Mara Salvatrucha".

Georges Balandier (1994) habla de la "teatrocracia" como una manera de regular la vida cotidiana de los seres humanos en colectividad, atribuye un elemento teatral a cada una de las expresiones de la vida social, particularmente en aquellas en las que el poder cobra un lugar relevante. Retomamos esta idea y la ampliamos en términos de que, en el ejercicio del poder, se da al mismo tiempo una producción de imágenes y un despliegue de símbolos ordenados en un sistema ritualizado. Por consiguiente $y$, agregando lo que propone Cohen (1979) con relación a lo simbólico, el ritual y el poder, destacamos que, en el ejercicio del poder, es viable "mirar" lo simbólico como mecanismo importante, es decir, los símbolos serían el vehículo a partir del cual se manifiestan las relaciones asimétricas de poder.

Si ligamos lo que menciona Balandier y Cohen, podríamos pensar que el ejercicio de la violencia en los espacios urbanos entre las pandillas juveniles de la "Mara Salvatrucha, MS13" v/s el "Barrio 18", tiene que ver, entre otras consideraciones, con la disputa del poder, es decir: el control del territorio, obtener prestigio social, ser respetados por los otros (no solo por las pandillas rivales, sino por la comunidad en la que viven), incluyendo la administración del miedo y el pánico social que generan con sus acciones.

Tal situación se estructura y construye a través de una serie de ritualizaciones como los de paso o iniciación; decíamos que, para entrar a la pandilla se tiran unos dados y el número que 
caiga son los minutos que el nuevo integrante tiene que soportar en golpes que le propinan sus compañeros. Esta representación se hace ante los demás y en el espacio público de la calle que regularmente controla la pandilla cuyo valor simbólico estriba en demostrar la valentía del nuevo miembro en el entendido de que, así como aguante la golpiza, así será de fuerte y valiente para defender a la pandilla en aquellas situaciones que se requieran o ameriten.

La estética corporal es central ya que ahí se nuclean aspectos identificatorios con la pandilla que da cuenta de los procesos de cohesión. Quizás el elemento más fuerte en cuanto a su carga simbólica sea la alteración y decoración del cuerpo, a través de los tatuajes. Regularmente, lo que se inscriben en la piel también es el nombre de la "clika" o la "gang", lo cual reafirma una especie de identidad grupal que ayuda también a ser reconocido por los otros y a difundir temor. También aparecen iconografías de las "jainas" (las mujeres), la virgen de Guadalupe y alusiones a determinados sucesos que regularmente están instalados en la ilegalidad.

Una parte de estos tatuajes son impresos en el espacio y el territorio de la cara y el rostro, diferencia sustancial con los "cholos", lo cual conlleva, además de una medida extrema y radical, una forma de interpelar (violentar), la mirada del "otro" o los "otros" que "miran". Marca también diferencia y ayuda a legitimarse al interior del agrupamiento o la pandilla, en tanto se demuestra arrojo y se instala en el lugar de lo temerario.

Así, el cuerpo o las corporalidades son representados y puestos en escena en el espacio público de la calle, configurado o construido a partir de los tatuajes, las gestualidades que aluden a las señas con las manos (regularmente "tirando barrio", el nombre de la pandilla a la que se pertenece), la manera de caminar, la mirada sostenida, el tipo de ropa que se usa, la forma de hablar y, en sí, la escenificación que se lleva a cabo con la finalidad de ganar respeto ante los otros, tanto similares como diferentes. 
Aquí, el asunto del respeto es central, ya que tiene que ver con el orgullo de ser de la pandilla, de ser "marero", o pertenecer a una etnia o raza, es decir, al vestirse "bien montado", se muestra una especie de poder simbólico, a través de todo ese andamiaje y esos signos que se construyen del lado de la pertenencia como miembro de esta pandilla que regularmente es temida.

Se trata de mostrar el poder de la presencia construida y representada a través de una serie de signos, símbolos y artefactos culturales que, sin duda, también dan cuenta de que se trata de agrupamientos juveniles urbanos situados en los procesos de la exclusión y la desigualdad social. Probablemente, esta representación y puesta en escena de la corporalidad de estos pandilleros de la "Mara Salvatrucha MS13", de una manera extrema y fuerte, e irrumpiendo la "mirada" de los otros, simbólicamente dé cuenta de la necesidad de incluirse en una sociedad que regularmente tiende a excluirlos. Una especie de recordatorio radical de que se está hablando y mostrando no solamente de las diferencias culturales, sino también las tensiones y las contradicciones irresueltas ancladas a las inequidades y las desigualdades sociales, en las que están inmersos muchos de ellos y ellas. En extenso, podemos decir que las bandas, las pandillas y la violencia asociada a los jóvenes, marcan parte de la vida cotidiana de las ciudades, las colonias y los barrios, de las comunidades más pobres y desfavorecidas de América Latina. Además, se construyen lógicas diferentes y muy particulares con respecto a los tiempos sociales, los espacios de la realidad y la particular administración del territorio, del miedo social y del poder.

En este sentido, ser pandillero (hombre o mujer), es una forma de vida a partir de la cual la violencia se va administrando, por lo que, al decir de Carlos Mario Perea 2004, los pandilleros hablan de la marginación y evidencian la crisis cultural y urbana en la que vive una gran parte de jóvenes en América Latina, teniendo como eje privilegiado sus cuerpos. 
Estas situaciones de violencia donde una parte de los jóvenes son sujetos de ella, es decir, la ejercen, tiene un impacto en los estados de ánimo y en las afectividades colectivas ya que generan bastante tensión social que favorece a las posturas más conservadoras y reaccionarias de la derecha de los países y que le da acción y protagonismo a las iniciativas de "mano dura", "de tolerancia cero", como a la reducción de la edad penal, a la pena de muerte, a la implementación de los toques de queda, a los grupos de autodefensa ciudadana o a la policía comunitaria (Colombia, Brasil) que violan los más elementales derechos humanos de estos jóvenes y que, en su acción, también se convierten en victimarios.

Este lugar de los jóvenes como victimarios de las violencias y también aunado a la participación irresponsable en la mayoría de los casos de los medios masivos de comunicación, ha favorecido la construcción de ciertas representaciones estigmatizadas en tanto señalarlos como los causantes y responsables de la violencia. Así, se ha creado una opinión pública dominante en contra de ellos y ellas que lo único que hace es crear más tensión y conflicto social, ya que no aporta absolutamente nada para la solución de los problemas asociados a las violencias. Por lo que convenimos con Elena Azaola (2004:9) cuando afirma: "[...] los jóvenes no son los únicos, y muchas veces ni siquiera los principales responsables de la violencia en nuestros países".

No me queda ninguna duda de que los jóvenes son los chivos expiatorios de los problemas sociales y la muestra del fracaso de la mayoría de los Estados Latinoamericanos y sus instituciones en términos de garantizar mejores condiciones de vida para su población, especialmente para los estratos histórica y culturalmente más desfavorecidos: los indígenas, los y las jóvenes, las mujeres, los ancianos, los pandilleros y todos aquellos que pertenezcan a los grupos en desigualdad y desventaja social y que se encuentran en situaciones límite. 


\section{Cuerpos y voces diferenciados (el género)}

$\mathrm{Si}$ consideramos que el género tiene que ver, entre otros aspectos, con la manera específica en que social y culturalmente se enseña y aprende a ser hombre o mujer en cualquier sociedad, entonces bien podríamos asegurar que este tipo de enseñanza y aprendizaje es distinto para cada uno. No es lo mismo lo que uno incorpora como hombre que lo que se interioriza siendo mujer, ni tampoco lo que la sociedad y sus instituciones, como por ejemplo la familia, la escuela o la religión "enseñan" y esperan de cada uno de los géneros, es decir, de lo masculino y lo femenino. De tal suerte que la diferencia entre géneros se convierte, en la mayoría de los casos, en desigualdad social.

A partir de esta situación, los vínculos intersubjetivos con el otro género, además de la distinción corporal, invariablemente estarán atravesados por diferencias construidas socioculturalmente. En la mayoría de los casos, devienen en ventajosas para los hombres (jóvenes) y desventajosas u opresivas para las mujeres (jóvenes); en otras palabras, los vínculos entre géneros implican relaciones de poder y dominación.

Con respecto a lo que llamaremos lo femenino -también desde las construcciones socioculturales- es importante recordar el pasaje de la década de los ochenta y la significativa presencia que tuvieron las mujeres jóvenes de la escena chola y punk. A través de sus tatuajes, empezaron a experimentar sus cuerpos y a vivirse a partir de su género. Algunos significados construidos eran precisamente a partir de esa diferencia sexual entre los géneros. De ahí que, para una parte de esas mujeres y de las nuevas adscripciones grupales juveniles contemporáneas ("cholillas" o "darketas", por ejemplo), la conciencia de la realidad de sus cuerpos es muy fuerte y llamativa y pasa por otro tipo de violencia, situación que no se observa en una gran parte de los hombres jóvenes del lado de sus adscripciones identitarias.

Esta conciencia particular de la corporalidad tiene que ver, 
entre otras cuestiones y como hipótesis, con su situación de ser mujeres, es decir, probablemente se genera más conciencia de una forma de violencia: la posesión y el riesgo de reproducir sin desearlo. De ahí la edificación de una percepción y autopercepción del cuerpo más cercana y presentista en una gran parte de las jóvenes mujeres que no pasa por el aniquilamiento del cuerpo de la "otra". Así, la práctica cultural del tatuaje cobra un sentido de reivindicación y autoafirmación en el uso y apropiación de sus cuerpos como género femenino, en tanto se apropian, probablemente, de lo que se les ha quitado.

Las primeras adscripciones identitarias juveniles urbanas que utilizaron el cuerpo tatuado y perforado en los espacios semipúblicos y públicos para interpelar y protestar abiertamente contra la sociedad excluyente fueron los "cholos", los jóvenes banda y los "punks". Ellos y ellas eran jóvenes de las principales ciudades del país y de bajos recursos económicos que, al alterar y decorar sus corporalidades, se apropiaban real como simbólicamente de sus cuerpos. Esto fue posibilitando la construcción de una geografía corporal armada a través de ciertas condiciones sociales de represión, de relajamiento, de distensión, invisibilidad y visibilidad que influían en los espacios y territorios del cuerpo elegidos para ser tatuados y/o perforados con la siguiente trayectoria; para los tatuajes, la ruta va de lo invisible a lo visible, es decir, de lo privado a lo público; y, para las perforaciones, de lo visible a lo invisible o de lo público a lo privado.

\section{Palabras finales}

El cuerpo juvenil urbano es un territorio y espacio mediado por la cultura y sus instituciones, en el cual -en algunos casos y dependiendo de la adscripción identitaria a la que se pertenezca- se hace visible el acto de la violencia simbólica representada a partir del tatuaje con una multiplicidad de sentidos y significados construidos social e individualmente. Por lo que, sin la idea del cuerpo, simplemente no se entendería este tipo de rostros de las 
violencias (sociales), ya que es el lugar o el territorio para dar cabida a las iconografías, las subjetividades, las diferencias asimétricas de género, los usos corporales, las decisiones de sí, la experiencia del dolor social y las condiciones socioculturales de la existencia de las violencias.

El cuerpo, entre otras circunstancias, está muy influido y determinado por la clase social, ya que pertenecer a un estrato socioeconómico bajo, habitar zonas populares, ser hombre o mujer joven y, además, ser parte de alguna adscripción identitaria urbana como la de los "cholos" y la "Mara Salvatrucha MS13", coloca a estas corporalidades juveniles en situaciones de mayor vulnerabilidad y las somete a una exposición de riesgo extremo. Por lo que aquellas situaciones y vivencias de violencia social que no son posibles de elaborar o entender en el nivel del psiquismo, justamente por ser crudas y duras, se les imprime o tatúa en el cuerpo físico.

Tanto el dolor físico como el emocional cobran una gran trascendencia, particularmente para el tatuaje, ya que el aspecto físico o biológico del sufrimiento corporal es rebasado y superado cargándolo de una serie de motivaciones personales, representaciones sociales y de valores simbólicos muy fuertes. De esta manera, el dolor se convierte en sufrimiento social, ya que funciona como una especie de trueque o intercambio a fin de hacerse acreedor no sólo de aquellas imágenes e iconografías elegidas, sino de un componente psicológico de elaboración simbólica que permita sortear a nivel del psiquismo las situaciones, los eventos y los acontecimientos difíciles de comprender en la vida cotidiana violenta, por lo que se requiere plasmarlos para siempre en el cuerpo.

\section{Bibliografía consultada}

Azaola, Elena (2004). "Presentación", en Revista Desacatos, Juventud: Exclusión y Violencia, México, CIESAS, pp. 7-11.

Balandier, Georges (1994). El poder en escenas. De la representación del poder al poder de la representación, Barcelona, Paidós. 
Bourgois, Philippe (2001). "The Continuum of Violence in War and Peace: Post-cold War Lessons from El Salvador", en Ethnography, vol. 2, Núm, 1, pp.5-34.

(2005). "Más allá de una pornografía de la violencia", en Ferrandiz, Francisco y Feixa, Carles (Eds.). Jóvenes sin tregua. Culturas y Políticas de la violencia, Barcelona, España. Anthropos.

Cohen, Abner (1979). "Antropología política: el análisis del simbolismo en las relaciones de poder", en J.R. Llobera (comp), Antropología política, Barcelona, Anagrama.

Cuerno, Lorena (2000). "El lado obscuro de la Calle. El caso extremo de la Mara", en Revista de Estudios sobre juventud, JOVENes, año 4, no. 10, enero-marzo, México. D.F., pp. 62-77.

Ferrandiz, F. y Feixa, C. (2004). "Una mirada antropológica sobre las violencias", en: Revista Alteridades, México, UAM-I, año 14, No. 27, enero-junio.

Kearney, Michael (1995). "The Local and the Global: The Antropology of Globalization and Trasnationalism", Annual Review of Anthropology, Vol, 24.

Krotz, Esteban (Comp.) (1993). La cultura adjetivada: el concepto de cultura en la antropología mexicana a través de sus adjetivaciones. México, UAM-I.

Organización Mundial de la Salud (2003). Informe mundial sobre la violencia y la salud (prevención), México, Nueva York. OPS/OMS.

Ortiz, Rubén (1994-1995). "Gang Art: pachucos, cholos, taggers, raperos, gangas, low riders", en Revista, La Pusmoderna, México.

Perea, Carlos Mario (2004). "Pandillas y conflicto urbano en Colombia", en Revista Desacatos, Juventud. Exclusión y Violencia, México, CIESAS, pp. 15-35.

Ramos, Luciana; Pérez, Enrique y Romero, Martha (1999). "La criminalización de la violencia juvenil. El caso del consumo de drogas". Revista de Estudios sobre Juventud, JOVENes, No.8, enero-junio, México.

Reguillo, Rossana (1999). "Violencias expandidas. Jóvenes y discurso social". Revista de Estudios sobre Juventud, JOVENes, No.8, enero-junio, México.

(2000). Emergencia de culturas juveniles. Estrategias del desencanto. Buenos Aires, Ed. Norma. 
Santa Cruz, María y Concha, Alberto (2001). Barrio Adentro. La solidaridad violenta de las pandillas, Organización Panamericana de la Salud, Instituto Universitario de Opinión Pública, Universidad Centroamericana "José Simeón Cañas", San Salvador, El Salvador, Centroamérica.

Soto, Adriana (2002). "La sospechosa relación entre juventud y violencia". México, Revista El Cotidiano, No. 111, enero-febrero.

Swartz, M; Turner, V. y A. Tuden (2004). “Antropología política: una introducción", Revista Alteridades, México, UAM-I, año 4, No.8.

Tilly, Charles (2003). The politics of collective violence, Cambridge University Press, Cambridge.

Valenzuela, José Manuel (1988). ¡A la brava ése! Cholos, punks, chavos banda. México, El Colegio de la Frontera Norte.

(2002). “De los pachuchos a los cholos. Movimientos juveniles en la frontera México-Estados Unidos", en Feixa, Molina y Alsinet (Coord.) Movimientos Juveniles en América latina. Pachucos, malandros, punketas, España, Ariel. 